\title{
Use and inhalation technique of inhaled medication in patients with asthma and COPD: data from a randomized controlled trial
}

Claudia Gregoriano ${ }^{1,2^{*}}$, Thomas Dieterle ${ }^{1,3}$, Anna-Lisa Breitenstein ${ }^{1}$, Selina Dürr', Amanda Baum', Sabrina Maier ${ }^{1}$, Isabelle Arnet ${ }^{2}$, Kurt E. Hersberger ${ }^{2}$ and Jörg D. Leuppi ${ }^{1,3}$

\begin{abstract}
Background: The burden of asthma and COPD among patients is high and people affected are frequently hospitalized due to exacerbations. There are numerous reasons for the lack of disease control in asthma and COPD patients. It is associated with non-adherence to guidelines on the part of the health care provider and with poor inhalation technique and/or non-adherence to the prescribed treatment plan by the patient. This study aims to present data on inhaler technique and its impact on quality of life (QoL) and symptom control in a typical population of patients with chronic lung disease from a randomized controlled trial on medication adherence.

Methods: For this cross-sectional analysis, 165 asthma and COPD patients were analyzed. Correct application of inhaler devices was tested using pre-defined checklists for each inhaler type. QoL and symptom control were investigated using COPD Assessment Test (CAT) and Asthma Control Test (ACT). Spirometry was used to measure forced vital capacity (FVC) and forced expiratory volume in one second $\left(\mathrm{FEV}_{1}\right)$.

Results: Overall, incorrect inhalation technique ranged from 0 to 53\% depending on the type of inhaler. COPD patients with incorrect device application had a higher CAT sum score compared to those with a correct device application $(P=.02)$. Moreover, COPD patients with incorrect device application were more likely to suffer from cough $(P=.03)$ and were more breathless while walking uphill or a flight of stairs $(P=.02)$. While there was no significance found in asthma patients, COPD patients who used their devices correctly had a significantly better mean $\mathrm{FEV}_{1} \%$ predicted at baseline compared to those who applied their devices incorrectly $(P=.04)$.

Conclusions: Correct inhalation of prescribed medication is associated with improved health status and lung function. These findings should encourage health professionals to provide instructions on correct inhalation technique and to regularly re-evaluate the patients' inhalation technique.
\end{abstract}

Trial registration: ClinicalTrials.gov: NCT0238672, Registered 14 February 2014.

Keywords: Asthma, Pulmonary disease, chronic obstructive, Inhalation technique, Dry powder inhalers, Metered dose inhalers, Quality of life, lung function

\footnotetext{
* Correspondence: claudia.gregoriano@ksbl.ch

${ }^{1}$ University Clinic of Medicine, Cantonal Hospital Baselland, Rheinstrasse 26,

$\mathrm{CH}-4410$ Liestal, Switzerland

${ }^{2}$ Department of Pharmaceutical Sciences, University of Basel, Basel,

Switzerland

Full list of author information is available at the end of the article
}

(c) The Author(s). 2018 Open Access This article is distributed under the terms of the Creative Commons Attribution 4.0 International License (http://creativecommons.org/licenses/by/4.0/), which permits unrestricted use, distribution, and reproduction in any medium, provided you give appropriate credit to the original author(s) and the source, provide a link to the Creative Commons license, and indicate if changes were made. The Creative Commons Public Domain Dedication waiver (http://creativecommons.org/publicdomain/zero/1.0/) applies to the data made available in this article, unless otherwise stated. 


\section{Background}

Asthma and Chronic Obstructive Pulmonary Disease (COPD) are chronic respiratory diseases that are highly prevalent in the overall population [1].

To date, asthma and COPD are not curable but treatable diseases of the respiratory system. Nevertheless, the burden of each disease among patients is high and patients may be frequently hospitalized due to exacerbation. Despite effective therapy options and evidence-based guidelines developed in recent years, disease control continues to be suboptimal in patients with these two chronic obstructive lung diseases.

There are numerous reasons for the lack of disease control in asthma and COPD patients. One important reason is the incorrect application of inhaler devices, which is associated with worsened health outcomes, such as increased risk of hospitalization and an insufficient diseases control [2-4].

Inhaled medication play a key role in the treatment of asthma and COPD patients. This application way has the advantage to deliver the drug directly into the airways. Therefore, high local concentrations can be achieved with a reduced risk of systemic side effects [5]. However, a variety of different sequential steps are necessary to achieve a correct application of these devices. Incorrect performance of one or more steps can substantially reduce the delivery of the administrated substance and consequently the effectiveness and safety of the medication [6]. Numerous studies have shown that $50-80 \%$ of the investigated patients do not use their inhaler devices correctly [7-10]. They often overestimate their inhalation technique or they are not even aware that they are using their inhaled medication incorrectly [11].

Therefore, as also recommended in national and international guidelines, inhalation technique should be assessed on a regular basis, in order to be able to correct the application if necessary.

This cross-sectional analysis aims to present data on inhaler technique and its impact on quality of life and symptom control in a typical population of patients with chronic lung disease from the Adherence-Trial [12]. The longitudinal Adherence-Trial was designed to investigate the effect of a patient-tailored intervention with daily alarm clock and reminder in form of phone calls on adherence to inhaled therapy in asthma and COPD patients and to determine the resulting effect on exacerbations and quality of life [12].

\section{Methods}

\section{Study design}

The Adherence-Trial was a single-blind randomized controlled trial. The study details have been published previously [12]. In brief, adherence to inhaled medication was analyzed over a six-month period in patients with asthma and/or COPD who experienced at least one exacerbation within the previous year. The study was conducted in an ambulatory setting between January 2014 and March 2017. The investigator obtained written consent from patients confirming their willingness to participate in the study. Adherence was measured using electronic data capture devices, which save date and time of each inhalation device actuation and transfer these data daily via wireless-connection to a web-based database. All participants took part in a training course before the baseline visit. The goal of the training course was to provide refresher training on inhalation techniques, to ensure that all participants were at the same level of knowledge about their disease and used their medication correctly. The training began with a brief introduction about asthma and COPD. Afterwards, the most frequently used devices were presented and briefly demonstrated. Common mistakes and problems associated with the use of the devices were explained. The correct use of the individual devices was demonstrated in a short film (produced by the "Deutsche Atemwegsliga" Bad Lippspringe, Germany) [13]. At the end of the training, participants were given the opportunity to ask questions concerning the devices. After the training course, patients were randomly assigned to either the intervention or the control group. The intervention group received a daily alarm clock and reminder in form of support calls in case medication was not taken as prescribed or the use of rescue medication doubled. During the study, participants were assessed every two months in the form of clinical visits. The detailed study procedure is illustrated in Fig. 1. Prior to initiation the trial was approved by the local ethics committee (registry number: EK-269/13) and registered (ClinicalTrials.gov: NCT02386722).

\section{Measurements}

\section{Sociodemographic factors}

Sociodemographic variables such as age, gender, marital status and education level were obtained by a generic questionnaire at the baseline visit. Furthermore, smoking status, as well as pack years (py) and body mass index (BMI) were recorded during this visit. In addition, disease-related questions like allergies, number of exacerbations during the previous 12 months including treatments with antibiotics, treatment with systemic corticosteroids, emergency department attendance and hospitalizations were asked. If patients were not able to provide information about the events, the treating physician was contacted. Moreover, the current inhaled medication was recorded. The respective diagnosed lung diseases (asthma, COPD or ACO) were taken from previous medical reports and were not redefined or diagnosed again for this study.

\section{Lung function}

Spirometry was used to measure forced vital capacity (FVC) and forced expiratory volume in one second 


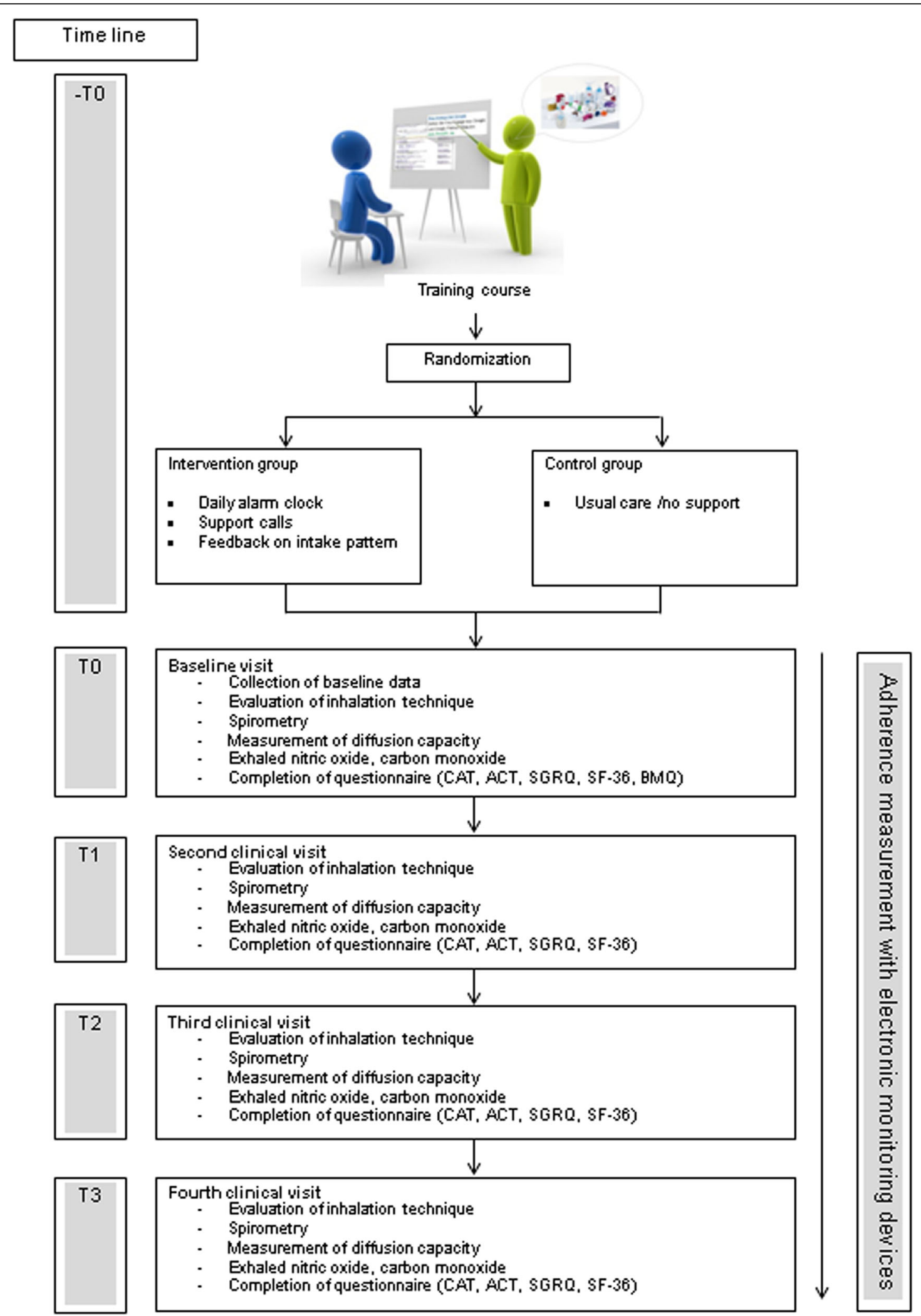

Fig. 1 Diagram for detailed study procedure 
$\left(\mathrm{FEV}_{1}\right)$. To obtain information about pulmonary gas transfer, diffusing capacity of the lung for carbon monoxide (DLCO) was measured. All tests were performed according to the guidelines of the European Respiratory Society [14]. The device EasyOne Pro (ndd Medizintechnik AG, Zürich, Switzerland) was used.

\section{Evaluation of the device application}

To detect false device application, each patient was asked to demonstrate the inhalation technique with all prescribed devices to the investigator by using a placebo device. As prescribed in the study protocol, correct use was assessed by using pre-defined checklists for each inhaler type based on user guidelines and instruction package inserts from the manufacturers. Inhaler technique was accepted as correct, when every step controlled in the checklist was performed accordingly. The technique was defined as wrong if one or more steps were done incorrectly. For each incorrect step, participants received a score of "0" whereas each correct application was valued as " 1 ". A critical error was defined as incorrect completion of a step that significantly reduces or totally inhibits drug delivery and thus impacts the effectiveness of the delivered drug [15]. Evaluation of the device application was assessed by a trained pharmacist. To standardize the observation of errors as much as possible, the same person (pharmacist) always evaluated the device application. Further, as part of the training, the pharmacist regularly watched inhaler videos [13] for the relevant devices types, in order to gain proficiency in the evaluation. The evaluation was performed by a single observer (intra-observer variability).

\section{Asthma control test (ACT)}

The ACT questionnaire was applied in order to assess asthma control. The validation of the questionnaire showed that scores calculated from the ACT are reliable and valid, and that the test has the ability to screen for patients with poorly controlled asthma. It represents a clinically validated measure of asthma control that is simple to administer to assess the level of asthma control with or without the use of lung function tests [16]. The ACT score ranges from 5 to 25 . Values ranging between 5 and 15 indicate "very poor controlled asthma", those from 16 to 19 "not well controlled asthma" and values varying from 20 to 25 signify "well controlled asthma" [16].

\section{Impact of COPD symptoms}

The health status of COPD patients was measured using the CAT (COPD Assessment Test). The CAT is a validated, disease-specific eight-item questionnaire on a sematic six-point differential scale. It is developed to measure the impact of the lung disease on patients' health status. Scores from 0 to $10,11-20,21-30$ and $31-40$ represent a "low", "medium", "high" and "very high" impact of the disease on a person's health status [17].

\section{Assessment of health-related quality of life}

Health-related quality of life was assessed using the St. George Respiratory Questionnaire (SGRQ), a standardized questionnaire developed for measuring impaired health and perceived well-being ("quality of life") in patients with asthma and COPD. Scores range from 0 to 100, with the highest scores indicating the poorest level of respiratory health as well as maximal disability $[18,19]$.

\section{Sample size calculation}

Power calculation is based on "time to next exacerbation", which was defined as primary endpoint of the overall Adherence-Trial. We expected an assumed endpoint reduction of $60 \%(12 / 30)$, with $12 \%(8 / 70)$ of patients experiencing an exacerbation in the intervention group. Assuming a sample size of 70 participants for each study group, there is a power of $80 \%$ to detect a hazard ratio (HR) of 0.36 based on a 1-tailed test with a $5 \%$-significance level, since only a decrease of the exacerbation-risk is of interest and expected. For each study group 7 additional participants were added to account for dropouts. Therefore, a minimum of 154 participants were included in this study.

\section{Statistical analysis}

Data were analyzed using the SPSS software package (version 23, IBM, Germany). Statistical significance was set at the $5 \%$ level. Data are presented as mean \pm standard deviation (SD) or number and percentage (\%). To check the data for normal distribution, the Shapiro-Wilk test was used. For two unrelated parametric conditions, the independent t-test was applied, while for two unrelated non-parametric conditions, the Mann-Whitney test was calculated. In order to investigate the relationship between categorical variables, the Pearson's chi-square test was applied. Poisson regression was used to quantify exacerbation count with respect to the participants' device handling before study start.

\section{Results}

A total of 169 asthma and COPD patients were recruited to participate in the study. Four patients withdrew after the training course. Therefore, a total of 165 patients (84 interventions, 81 controls) were assessed and analyzed at baseline (Fig. 2).

\section{Patients' characteristics}

Patients' characteristics are presented in Table 1. Approximately $40 \%$ of the asthma patients had not well- or poorly controlled asthma at baseline, while less than 
Recruitment by advertisement (posters, flyers, ad-screen, advertisement in local newspapers) $(n=66)$
Recruitment by screening of hospitalized patients, emergency department, DRG-lists and collaboration with pulmonology department $(n=459)$
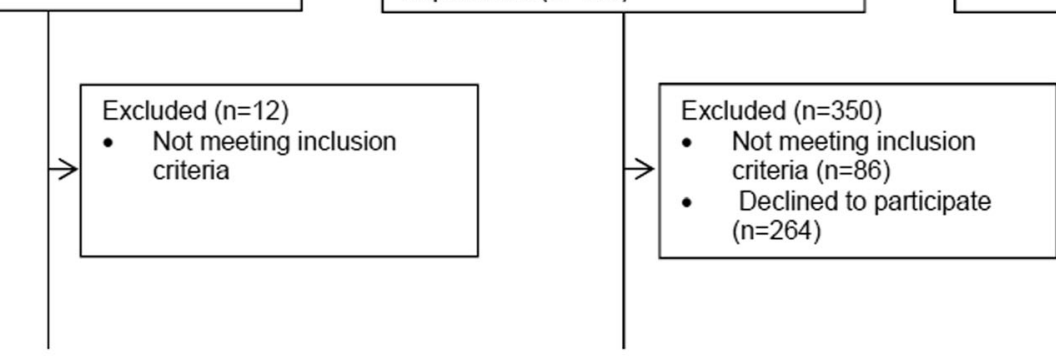

Recruitment by other hospitals and pulmonologists in private practice $(n=6)$

$(n=54)$ $(n=109)$ $(n=6)$

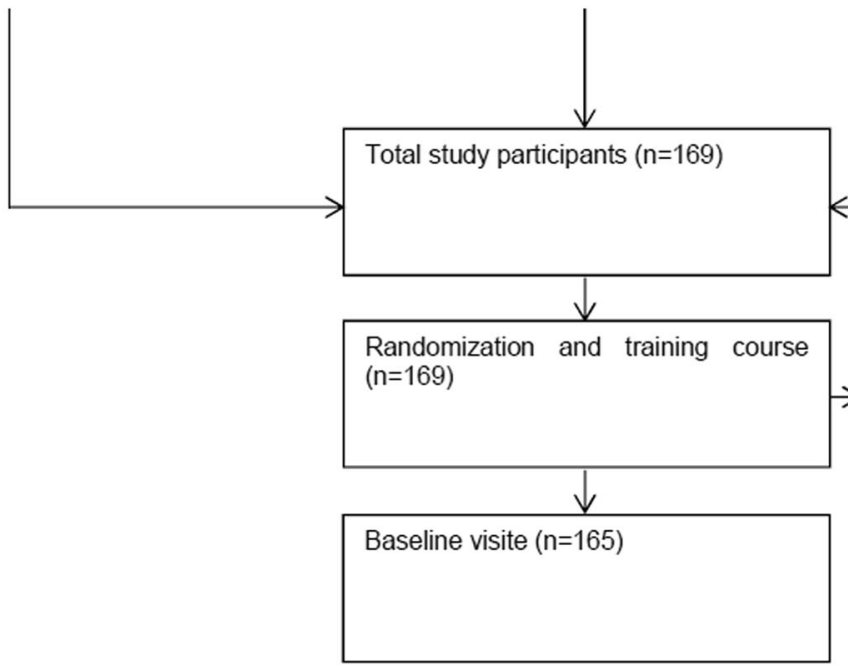

Fig. 2 Flow chart of study

$30 \%$ of the COPD patients showed a high- and very high impact of the disease on their health status.

A summary of the prescribed medication at baseline is illustrated in Table 2 . The most frequently prescribed inhaled medications were combinations of LABA and ICS (35.5\%), followed by LABA (23.0\%) and SABA (20.9\%). The majority of the participating patients had dual therapy with a combination of two inhaled medications $(44.8 \%)$ or monotherapy with only one inhaled medication $(29.7 \%)$.

\section{Device application considering the different inhaler types}

Table 3 shows the quality of device application subdivided into the different inhaler types used by the study participants. Other devices (e.g. Genuair etc.) not specified in Table 3 were not used by the participants and thus not examined. Overall, incorrect inhalation technique ranged from 0 to $53 \%$ depending on the type of inhaler. The highest rate of incorrect device application was identified among patients using metered dose inhalers. Followed by those who applied Turbohaler as well as powder inhalation capsules such as Handihaler and Breezhaler. Patients who showed a higher number of correct device applications either used the Discus or the newest powder device Ellipta. Table 3 shows the number of errors for each investigated device. When following the pre-defined checklists, which varied according to each inhaler type, there were some steps associated with a considerable number of repeated errors. For the metered dose inhaler with or without spacer, the steps "shake the inhaler before actuation" was performed incorrectly in $37 \%(n=23)$, while the step "coordination of actuation and inhalation" which regards only the metered dose inhaler without spacer represented a source of error in $20 \%(n=17)$ of patients. Also the "deep and slow" inspiration that is needed for a complete and correct inhalation of the aerosol delivered by the metered dose inhaler was one of the most common points that caused problems $(17 \%, n=14)$. In case of the Turbohaler application, $30 \%(n=17)$ of the patients did not ensure that the device was held upright while charging in order to achieve correct dose loading. 
Table 1 Characteristics of the 165 study participants at baseline

\begin{tabular}{|c|c|c|c|c|}
\hline \multirow[t]{2}{*}{ Variable } & \multicolumn{4}{|c|}{ Number(\%) or Mean \pm SD } \\
\hline & $\begin{array}{l}\text { All } \\
(n=165)\end{array}$ & $\begin{array}{l}\text { Asthma } \\
(n=50)\end{array}$ & $\begin{array}{l}\text { COPD } \\
(n=89)\end{array}$ & $\begin{array}{l}\text { ACO } \\
(n=26)\end{array}$ \\
\hline Age & $66.8 \pm 11.5$ & $61.1 \pm 15.1$ & $69.8 \pm 8.5$ & $67.2 \pm 8.0$ \\
\hline Male & $106(64.2)$ & $23(46)$ & $63(70.8)$ & $20(76.9)$ \\
\hline \multicolumn{5}{|l|}{ Marital status } \\
\hline Unmarried & 19 (11.5) & $7(14)$ & $11(12.4)$ & $1(3.8)$ \\
\hline Married & $104(63.0)$ & $33(66)$ & $51(57.3)$ & $20(76.9)$ \\
\hline Divorced/widowed & $42(25.5)$ & $10(20)$ & $27(30.3)$ & $5(19.2)$ \\
\hline \multicolumn{5}{|l|}{ Highest level of education at school } \\
\hline Primary school & $27(16.4)$ & $6(12)$ & $18(20.2)$ & $3(11.5)$ \\
\hline Apprenticeship & $97(58.8)$ & $25(50)$ & $55(61.8)$ & $17(65.4)$ \\
\hline Higher professional education & $22(13.3)$ & $7(14)$ & $11(12.4)$ & $4(15.4)$ \\
\hline University-entrance Diploma/Commercial college & $3(1.8)$ & $3(6)$ & $0(0)$ & $0(0)$ \\
\hline University /College of higher education & $16(9.7)$ & $9(18)$ & $5(5.6)$ & $2(7.7)$ \\
\hline \multicolumn{5}{|l|}{ Smoking status } \\
\hline Current smokers & $32(19.4)$ & $5(10)$ & $24(27)$ & $3(11.5)$ \\
\hline Non-smokers & $37(22.4)$ & $28(56)$ & $5(5.6)$ & $4(15.4)$ \\
\hline Ex-smokers & $96(58.2)$ & $17(34)$ & $60(67.4)$ & $19(73.1)$ \\
\hline Pack-years & $35.0 \pm 34.3$ & $8.0 \pm 14.3$ & $58.5 \pm 33.0$ & $32.3 \pm 35.5$ \\
\hline Body mass index $\left[\mathrm{kg} / \mathrm{m}^{2}\right]$ & $27.2 \pm 5.1$ & $26.9 \pm 3.9$ & $26.9 \pm 5.6$ & $28.5 \pm 5.3$ \\
\hline \multicolumn{5}{|l|}{ GOLD stage $(n=115)$} \\
\hline $1\left(\mathrm{FEV}_{1}>80 \%\right.$ predicted $)$ & $8(6.9)$ & & $6(6.7)$ & $2(7.7)$ \\
\hline $2\left(\mathrm{FEV}_{1}, 50-80 \%\right.$ predicted) & $47(40.9)$ & & $33(37.1)$ & $14(53.8)$ \\
\hline $3\left(\mathrm{FEV}_{1} 30-50 \%\right.$ predicted) & $46(40.0)$ & & $36(40.4)$ & $10(38.5)$ \\
\hline $4\left(\mathrm{FEV}_{1}<30 \%\right.$ predicted $)$ & $14(12.2)$ & & $14(15.7)$ & $0(0)$ \\
\hline \multicolumn{5}{|l|}{ Lung function parameters } \\
\hline $\mathrm{FEV}_{1} \%$ predicted & $59.9 \pm 24.5$ & $80.0 \pm 19.9^{\mathrm{a}}$ & $48.2 \pm 20.0$ & $61.9 \pm 21.1^{b}$ \\
\hline FVC $\%$ predicted & $90.2 \pm 19.0$ & $98.7 \pm 17.7^{\mathrm{a}}$ & $85.0 \pm 18.4$ & $92.3 \pm 17.6^{b}$ \\
\hline $\mathrm{FEV}_{1} / \mathrm{FVC}$ ratio & $51.9 \pm 16.7$ & $66.3 \pm 12.3^{\mathrm{a}}$ & $43.7 \pm 13.9$ & $52.9 \pm 14.3^{b}$ \\
\hline DLCO \% predicted & $72.2 \pm 21.8$ & $88.9 \pm 15.7$ & $61.1 \pm 19.2$ & $78.0 \pm 17.5$ \\
\hline \multicolumn{5}{|l|}{ Asthma Control Test $(n=76)$} \\
\hline Sum score & $19.5 \pm 4.5$ & $20.7 \pm 3.8$ & & $17.15 \pm 5.0$ \\
\hline Poorly controlled & $15(19.7)$ & $5(10)$ & & $10(38.5)$ \\
\hline Not well-controlled & $14(18.4)$ & $8(16)$ & & $6(23.1)$ \\
\hline Well controlled & $47(61.9)$ & $37(74)$ & & $10(38.5)$ \\
\hline \multicolumn{5}{|l|}{ COPD Assessment Test $(n=115)$} \\
\hline Sum score & $16.1 \pm 7$ & & $16 \pm 7$ & $16.6 \pm 7.2$ \\
\hline Low impact & $25(21.8)$ & & $19(21.3)$ & $6(23.1)$ \\
\hline Medium impact & $58(50.4)$ & & $46(51.7)$ & $12(46.2)$ \\
\hline High impact & $29(25.2)$ & & $22(24.7)$ & $7(26.9)$ \\
\hline Very high impact & $3(2.6)$ & & $2(2.2)$ & $1(3.8)$ \\
\hline \multicolumn{5}{|l|}{ SGRQ $(n=165)$} \\
\hline Symptoms score & $47.0 \pm 24.1$ & $35.9 \pm 19.1$ & $50.6 \pm 23.6$ & $55.9 \pm 27.9$ \\
\hline Activity score & $48.6 \pm 22.3$ & $34.5 \pm 21.0$ & $54.9 \pm 20.2$ & $54.4 \pm 20.0$ \\
\hline
\end{tabular}


Table 1 Characteristics of the 165 study participants at baseline (Continued)

\begin{tabular}{|c|c|c|c|c|}
\hline \multirow[t]{2}{*}{ Variable } & \multicolumn{4}{|c|}{ Number(\%) or Mean \pm SD } \\
\hline & $\begin{array}{l}\text { All } \\
(n=165)\end{array}$ & $\begin{array}{l}\text { Asthma } \\
(n=50)\end{array}$ & $\begin{array}{l}\text { COPD } \\
(n=89)\end{array}$ & $\begin{array}{l}\text { ACO } \\
(n=26)\end{array}$ \\
\hline Impact score & $25.6 \pm 18.1$ & $19.1 \pm 15.4$ & $27.6 \pm 17.7$ & $31.1 \pm 21.0$ \\
\hline Total Score & $36.1 \pm 18.1$ & $26.6 \pm 15.4$ & $39.6 \pm 17.2$ & $42.3 \pm 19.6$ \\
\hline Known allergies & $68(41.2)$ & $33(66)$ & $17(19.1)$ & $18(69.2)$ \\
\hline \multicolumn{5}{|c|}{ Number of exacerbations in the past 12 months } \\
\hline 1 & $92(55.8)$ & $29(58)$ & $50(56.2)$ & $13(50)$ \\
\hline 2 & $28(17)$ & $11(22)$ & $15(16.9)$ & $2(7.7)$ \\
\hline 3 & $21(12.7)$ & $5(10)$ & $10(11.2)$ & $6(23.1)$ \\
\hline$>3$ & $24(14.5)$ & $5(10)$ & $14(15.7)$ & $5(19.2)$ \\
\hline \multicolumn{5}{|c|}{ Number of antibiotic treatments in the past 12 months } \\
\hline Never & $13(7.9)$ & $8(16)$ & $4(4.5)$ & $1(3.8)$ \\
\hline Once & $91(55.2)$ & $29(58)$ & $50(56.2)$ & $12(46.2)$ \\
\hline $2-3$ times & $43(26.1)$ & $12(24)$ & $23(25.8)$ & $8(30.8)$ \\
\hline More than 3 times & $18(10.9)$ & $1(2)$ & $12(13.5)$ & $5(19.2)$ \\
\hline \multicolumn{5}{|c|}{ Number of systemic corticosteroid treatments in the past 12 months } \\
\hline Never & $77(46.7)$ & $23(46)$ & $44(49.4)$ & $10(38.5)$ \\
\hline Once & $44(26.7)$ & $12(24)$ & $26(29.2)$ & $6(23.1)$ \\
\hline $2-3$ times & $19(11.5)$ & $7(14)$ & $7(7.9)$ & $5(19.2)$ \\
\hline More than 3 times & $25(15.2)$ & $8(16)$ & $12(13.5)$ & $5(19.2)$ \\
\hline \multicolumn{5}{|c|}{ Number of emergency department attendance } \\
\hline Never & $103(62.4)$ & $40(80)$ & $48(53.9)$ & $15(57.7)$ \\
\hline Once & $44(26.7)$ & $8(16)$ & $28(31.5)$ & $8(30.8)$ \\
\hline 2-3 times & $16(9.7)$ & $2(4)$ & $11(12.4)$ & $3(11.5)$ \\
\hline More than 3 times & $2(1.2)$ & $0(0)$ & $2(2.2)$ & $0(0)$ \\
\hline \multicolumn{5}{|c|}{ Number of exacerbations with hospitalization in the past 12 months } \\
\hline Never & $97(58.8)$ & $39(78)$ & $43(48.3)$ & $15(57.7)$ \\
\hline Once & $51(30.9)$ & $7(14)$ & $34(38.2)$ & $10(38.5)$ \\
\hline 2-3 times & $14(8.5)$ & $4(8)$ & $9(10.1)$ & $1(3.8)$ \\
\hline More than 3 times & $3(1.8)$ & $0(0)$ & $3(3.4)$ & $0(0)$ \\
\hline
\end{tabular}

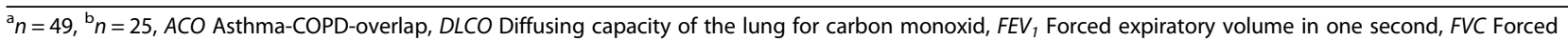
vital capacity, SGRQ St. George Respiratory Questionnaire

Furthermore, 9\% $(n=6)$ of the patients who applied the Handihaler did not "breathe out completely before the inhalation" and did not "hold breath for at least $5 \mathrm{sec}$ onds after inhalation" $(9 \%, n=6)$. Moreover, $13 \%(n=5)$ of the participants using Breezhaler devices showed "multiple squeezing of the pushbutton to pierce the capsule". It has to be noted that multiple piercing can cause the capsule to break into particles which requires full replacement of the capsule.

Table 4 shows how often inhaler usage of the specified devices was explained by a health care provider at the time it was first prescribed. The education was carried out most frequently by a pulmonologist $(45 \%, n=108)$ followed by a general practitioner in $36 \%(n=87)$ of the cases. Nurses $(8 \%, n=18)$, pharmacists $(4 \%, n=10)$ and physiotherapists $(3 \%, n=7)$ seem not to play an important role in the education of device usage. Six patients indicated to have received education from a general practitioner as well as from a pulmonologist (3\%) and further three patients received instruction from a general practitioner and a physiotherapist (1\%).

\section{Relationship between exacerbation history and device application}

Table 5 illustrates the exacerbation history of the 12 months before inclusion in relation to the device handling of the participants. The poisson regression indicated that patients with incorrect inhaler handling, had 1.30 (95\% CI,1.04 to 1.63 ) or $30 \%$ times more exacerbations compared to participants with correct inhaler handling. 
Table 2 Characteristics of the prescribed medication of the 165 study participants at baseline

\begin{tabular}{lllll}
\hline Variable & \multicolumn{4}{l}{ Number (\%) } \\
\cline { 2 - 5 } & $\begin{array}{l}\text { All } \\
(n=165)\end{array}$ & $\begin{array}{l}\text { Asthma } \\
(n=50)\end{array}$ & $\begin{array}{l}\text { COPD } \\
(n=89)\end{array}$ & $\begin{array}{l}\text { ACO } \\
(n=26)\end{array}$ \\
\hline $\begin{array}{lllll}\text { Medication }(n=326) \\
\text { LABA/ LAMA combinations }\end{array}$ & $21(6.4)$ & $1(0.3)$ & $16(4.9)$ & $4(1.2)$ \\
LABA/ICS combinations & $116(35.5)$ & $44(13.5)$ & $50(15.3)$ & $22(6.7)$ \\
LAMA & $75(23)$ & $5(1.5)$ & $60(18.4)$ & $10(3.1)$ \\
LABA & $23(7)$ & $3(0.9)^{a}$ & $15(4.6)$ & $5(1.5)$ \\
ICS & $17(5.2)$ & $8(2.5)$ & $4(1.2)$ & $5(1.5)$ \\
SAMA & $2(0.6)$ & $1(0.3)$ & $1(0.3)$ & $0(0)$ \\
SABA & $68(20.9)$ & $28(8.6)$ & $31(9.5)$ & $9(2.8)$ \\
SABA/SAMA combinations & $4(1.2)$ & $0(0)$ & $1(0.3)$ & $3(0.9)$ \\
Number of inhaled medication at baseline & & & \\
1 & $50(30.3)$ & $17(34)$ & $27(30.3)$ & $6(23.1)$ \\
2 & $71(43)$ & $26(52)$ & $37(41.6)$ & $8(30.8)$ \\
3 & $42(25.5)$ & $7(14)$ & $23(25.8)$ & $12(46.2)$ \\
4 & $2(1.2)$ & $0(0)$ & $2(2.2)$ & $0(0)$ \\
\hline
\end{tabular}

ACO Asthma-COPD-overlap, LABA Long acting beta ${ }_{2}$-agonist, LAMA Long acting muscarinic antagonist, ICS Inhaled corticosteroid, SAMA Short acting muscarinic antagonist; SABA, Short acting beta ${ }_{2}$-agonist

${ }^{\text {a The }} 3$ asthma patients with a LABA-medication also had an ICS medication as part of their treatment plan (in separate devices and not as a combined preparation). Thus, monotherapy with LABA in asthmatic patients did not occur due to the fact that it can increase the exacerbation risk by masking the asthma symptoms (FDA Drug Safety Communication [38])

\section{Comparison of ACT and CAT between patients with correct and incorrect device application at baseline}

$\mathrm{ACT}$ and CAT sum scores between asthma, respectively COPD patients with correct and incorrect device application are shown in Table 6. Regarding asthma control, no difference was observed between asthma patients with correct and incorrect device application $(P=.99)$. In contrast, COPD patients with incorrect device application had a higher CAT sum score compared to those with a correct device application $(P=.02)$.

A subgroup analysis of the single ACT and CAT questions between patients with correct and incorrect device application is also illustrated in Table 6. There was no significant difference for all ACT-questions. However, for the CAT questions there was a significant difference in the question referring to the frequency of cough $(P=.03)$ and the question assessing the condition of being "breathless while walking up a hill or flight of stairs" $(P=.02)$.

\section{Comparison of lung function parameters between patients with correct and incorrect device application at baseline}

The comparison of the forced expiratory volume in one second $\left(\mathrm{FEV}_{1}\right)$ (Fig. 3) and the Tiffeneau $\left(\mathrm{FEV}_{1} / \mathrm{FVC}\right)$ (Fig. 4) between asthma patients with correct and incorrect device application showed no difference. However,
COPD patients who applied their devices correctly had a significantly better mean $\mathrm{FEV}_{1}$ at baseline compared to those who applied their devices incorrectly $(P=.04)$.

DLCO values between participants with correct and incorrect device application showed no difference neither for patients with asthma nor with for patients with COPD (Fig. 5).

\section{Discussion}

\section{Main findings}

Overall, the application of metered dose inhalers and dry powder inhalers, such as Turbohalers and Breezhaler, showed more incorrect application by the patients while the devices such as Discus and Ellipta ${ }^{\circledR}$ were used more often correctly. In asthma patients, device application had no impact - neither on the ACT score nor on the lung function parameters. However, in COPD patients, incorrect device application had a negative impact on the CAT score. Furthermore, those who applied their devices correctly had a better forced expiratory volume in one second $\left(\mathrm{FEV}_{1}\right)$.

\section{Patient characteristics}

In our study, patient characteristics appeared to be comparable to previous studies with regard to the perception of disease. Thus, $40 \%$ of the asthma patients indicated that their disease was not well- or poorly controlled while $30 \%$ of the COPD patients stated a high or very high impact of the ailment on their health status. These results are comparable to prior studies by Guénette et al., where $48 \%$ of the patients reported uncontrolled asthma [20] and by Dürr et al. where $34 \%$ of the patients had uncontrolled asthma at baseline [21]. The mean CAT sum score was 16.7 in COPD patients at baseline, indicating a medium impact on health status - a value also observed in the PHARMACOP study, which examined the effectiveness of a pharmaceutical care programme in patients suffering from COPD [22].

\section{Device application and different inhaler types}

Correct handling of inhaler devices was found to be very type-specific. Metered dose inhalers were more frequently applied in an incorrect way among the study population than dry powder inhalers. The same phenomenon was observed for dry powder inhalers like Turbohaler, Handihaler and Breezhaler. In contrast, the use of the dry powder inhaler Ellipta ${ }^{\circledR}$ was more often correct in the investigated sample.

Frequent application errors identified in the study population were also confirmed by other studies. The results of the CRITIKAL study named the step of "coordination of actuation and inhalation" as one of the main errors in the application process of metered dose inhaler with an error rate of $37 \%$ [23]. 
Table 3 Number of errors after the training course for each device

\begin{tabular}{|c|c|c|c|c|c|c|c|}
\hline \multirow[t]{3}{*}{ Variable } & \multicolumn{7}{|c|}{ Number (\%) } \\
\hline & $\mathrm{MDI}$ & MDI-spacer & Discus & Turbo-haler & Handi- haler & Breez- haler & Ellipta $^{\oplus}$ \\
\hline & $(n=60)$ & $(n=24)$ & $(n=31)$ & $(n=57)$ & $(n=66)$ & $(n=40)$ & $(n=22)$ \\
\hline At least one error & $32(53)$ & $6(25)$ & $4(13)$ & $22(39)$ & $14(21)$ & $10(25)$ & $0(0)$ \\
\hline \multicolumn{8}{|l|}{ Handling error } \\
\hline Not removing/opening the $\operatorname{cap}^{\mathrm{a}}$ & $0(0)^{a}$ & $0(0)^{a}$ & N.A & $0(0)^{a}$ & N.A & $-\mathrm{N} . \mathrm{A}$ & N.A \\
\hline Not shaking the device before actuation & $20(24)^{a}$ & $3(13)^{a}$ & N.A & N.A & N.A & N.A & N.A \\
\hline No upright posture before inhalation & $1(1)$ & $0(0)$ & $1(3)$ & $0(0)$ & $1(2)$ & $1(3)$ & $0(0)$ \\
\hline $\begin{array}{l}\text { Poor coordination of actuation and inhalation: } \\
\text { triggering before or at end of inspiration }{ }^{a}\end{array}$ & $17(20)^{a}$ & N.A & N.A & N.A & N.A & N.A & N.A \\
\hline Failure to pierce the capsules & N.A & N.A & N.A & N.A & $2(3)^{a}$ & $5(13)^{a}$ & N.A \\
\hline Incorrect rotation & N.A & N.A & N.A & $2(3.51)^{a}$ & N.A & N.A & N.A \\
\hline Incorrect inhaler position ${ }^{a}$ & $0(0)$ & $0(0)$ & $0(0)$ & $17(29.82)^{a}$ & N.A & N.A & N.A \\
\hline Failure to load & N.A & N.A & $1(3)^{\mathrm{a}}$ & N.A & $0(0)^{a}$ & $2(5)^{a}$ & N.A \\
\hline Failure to open the device & N.A & N.A & $0(0)^{a}$ & N.A & $0(0)^{a}$ & $0(0)^{a}$ & $0(0)^{a}$ \\
\hline Mouthpiece not enclose tightly with the lips ${ }^{a}$ & $6(7)^{\mathrm{a}}$ & $0(0)^{a}$ & $0(0)^{a}$ & $1(1.75)^{\mathrm{a}}$ & $2(3)^{a}$ & $0(0)^{a}$ & $0(0)^{a}$ \\
\hline \multicolumn{8}{|l|}{ Inhalation error } \\
\hline Not holding breath for about $5 \mathrm{~s}$ after inhalation ${ }^{a}$ & $6(7)$ & $1(4)$ & $1(3)$ & $2(3.51)$ & $6(9)$ & $1(3)$ & $0(0)$ \\
\hline No complete expiration before inhalation ${ }^{a}$ & $5(6)$ & $1(4)$ & $2(7)$ & $4(7.02)$ & $6(9)$ & $2(5)$ & $0(0)$ \\
\hline Expiration into the device ${ }^{a}$ & N.A & N.A & $0(0)^{a}$ & $0(0)^{a}$ & $0(0)^{a}$ & $0(0)^{a}$ & $0(0)^{a}$ \\
\hline No deep and slow inspiration & $14(17)$ & $2(8)$ & N.A & N.A & N.A & N.A & N.A \\
\hline No forceful and deep inspiration ${ }^{a}$ & N.A & N.A & $1(3)$ & $3(5.26)$ & $1(2)$ & $2(5)$ & $0(0)$ \\
\hline No vibration of the capsule audible, during inhalation & N.A & N.A & N.A & N.A & $1(2)^{a}$ & $1(3)^{a}$ & N.A \\
\hline No breathing out with pursed up lip technique after inhalation & $0(0)$ & $0(0)$ & $1(3)$ & $0(0)$ & $1(2)$ & $0(0)$ & $0(0)$ \\
\hline
\end{tabular}

${ }^{\mathrm{a} C r i t i c a l}$ errors for this device [15]. MDI, metered dose inhaler; N.A., not applicable for the corresponding device

Similar handling errors with the Handihaler were reported by Kiser et al. [24]. In this study, breath-holding for a sufficient amount of time after inhalation was identified to be performed wrong in $40 \%$ of the cases. Even after an intervention, 30\% of the Handihaler applications were performed incorrectly.

Since the correct use of an inhaler by patients is directly related to high drug delivery at the target location

Table 4 Inhaler-usage-education before study start

\begin{tabular}{llll}
\hline \multirow{2}{*}{ Device } & & \multicolumn{2}{l}{ Previous inhaler usage education } \\
\cline { 3 - 4 } & & $\begin{array}{l}\text { Education } \\
\text { Number (\%) }\end{array}$ & No education \\
\hline Metered dose inhaler & 84 & $65(77)$ & $19(23)$ \\
With Spacer & 24 & $19(79)$ & $5(21)$ \\
Without Spacer & 60 & $46(77)$ & $14(23)$ \\
Discus & 31 & $29(94)$ & $2(6)$ \\
Turbohaler & 57 & $47(82)$ & $10(18)$ \\
Handihaler & 66 & $54(82)$ & $12(18)$ \\
Breezhaler $_{\text {Ellipta }}$ & 40 & $29(73)$ & $11(27)$ \\
\hline
\end{tabular}

to the efficacy of the therapy and thereby for sufficient disease control $[9,25,26]$, the selection of an adequate inhaler type taking into account the skills and preferences of the individual patient is an important aspect with regard to therapeutic success. This underlines the recommendation by Hodder et al., who stated that the satisfaction and preference of a patient for his inhaler device seems to have a potential impact on the adherence to therapy and consequently on the long-term outcomes of the disease [27].

The good applicability of the Ellipta device can certainly be explained by the fact, that the application itself is very simple. However, compared to the Discus, there are not many differences regarding the application. Nevertheless, the correct handling of an Ellipta ${ }^{\circ}$ device seems to be easier. It has to be noted that Ellipta ${ }^{\circ}$ devices have just been introduced to the market. Therefore, the instructions for correct use provided by a doctor or pharmacist might be more detailed and informative compared to information related to older inhalation devices.

At any rate, the findings from the Adherence-Trial underline the importance of providing a comprehensive introduction to newly prescribed medications and a continuous educational training regarding patient's recent 
Table 5 Exacerbation history in relation to the device handling of the participants

\begin{tabular}{|c|c|c|c|c|c|c|c|}
\hline Exacerbation history & Count & 1 & 2 & 3 & 4 & 5 & 6 \\
\hline Correct inhaler handling $(n=104)$ & Frequency (\%) & $66(63)$ & $18(17)$ & $8(8)$ & $8(8)$ & $4(4)$ & $0(0)$ \\
\hline Incorrect Inhaler handling $(n=61)$ & Frequency (\%) & $26(43)$ & $10(16)$ & $13(21)$ & $10(16)$ & $1(2)$ & $1(2)$ \\
\hline
\end{tabular}

developments in disease and therapy. This is particularly important in order to ensure that patients are continuously and actively involved in the treatment procedure [21]. Furthermore, these findings reconfirm the recommendation by the Global Initiative for Asthma (GINA) and Global Initiative for Chronic Obstructive Lung Disease (GOLD) guidelines to regularly re-evaluate the correct device application to prevent faulty long-term device use $[5,28]$.

\section{Exacerbation history and device application}

Participants using their inhaled devices with at least one handling error (minor or critical errors) had significantly more exacerbations in the 12 months before study start compared to participants with a correct handling of their inhaled medication. However, the comparison of participants with at least one critical error and participants with minor errors showed no significant difference with respect to the exacerbation history. These results could also be confirmed by previous studies which demonstrated that device handling errors including critical errors are associated with severe exacerbations [23, 29, 30].

\section{ACT and CAT scores and correct/incorrect device application at baseline}

In asthma patients, the comparison of the ACT sum score as well as the individual ACT questions with the correct/ incorrect device application did not indicate any difference at baseline. This can be explained by the fact that all patients had to be in a stable condition and free of exacerbation for at least one month at the time of their inclusion into the study. Generally, asthma patients show none to very few symptoms during a stable phase of their disease. Moreover, all participants suffering from asthma had an ACT mean sum score of around 20, signifying well-controlled disease condition at that point of time.

However, one could assume that an observation of patients in an acute deterioration phase would indicate a difference when comparing the ACT sum score with the correct/ incorrect device application. Patients applying their inhalation device correctly would be expected to benefit more from the inhaled medication and would therefore show better symptom control compared to patients who use their device incorrectly. Price et al. conducted a real-life study with asthma patients, that showed that there is a difference between the type of

Table 6 Comparison of ACT and CAT between patients with correct and incorrect device application at baseline

\begin{tabular}{|c|c|c|c|}
\hline \multirow[b]{2}{*}{ Device application } & \multicolumn{2}{|l|}{ Mean $(95 \% \mathrm{Cl})$} & \multirow[t]{2}{*}{$P$ value } \\
\hline & Correct & Incorrect & \\
\hline ACT total sum score & $19.40(18.04-20.75)$ & $19.61(17.93-21.28)$ & .99 \\
\hline CAT total sum score & $14.97(13.48-16.47)$ & $18.07(15.70-20.44)$ & .02 \\
\hline \multicolumn{4}{|l|}{ ACT- questions (referring to the last 4 weeks): } \\
\hline Question 1: Prevention to go work/school & $3.90(3.57-4.22)$ & $4.00(3.58-4.42)$ & .71 \\
\hline Question 2: Shortness of breath & $3.63(3.23-4.02)$ & $3.54(3.02-4.05)$ & .71 \\
\hline Question 3: Asthma symptoms at night & $3.75(3.33-4.17)$ & $4.04(3.55-4.52)$ & .47 \\
\hline Question 4: Use of reliever medication & $4.13(3.75-4.50)$ & $4.11(3.67-4.55)$ & .65 \\
\hline Question 5: Self-assessment of asthma control & $4.00(3.73-4.27)$ & $3.93(3.63-4.23)$ & .51 \\
\hline \multicolumn{4}{|l|}{ CAT- questions: } \\
\hline Question 1: Frequency of cough & $2.22(1.91-2.53)$ & $2.79(2.35-3.23)$ & .03 \\
\hline Question 2: Amount of phlegm & $2.10(1.80-2.39)$ & $2.60(2.11-3.10)$ & .08 \\
\hline Question 3: Tightness in the chest & $1.72(1.44-2.00)$ & $2.09(1.61-2.58)$ & .22 \\
\hline Question 4: Breathlessness while walking up a hill or one flight of stairs & $3.18(2.84-3.52)$ & $3.77(3.38-4.16)$ & .02 \\
\hline Question 5: Limitation doing activities at home & $1.81(1.45-2.16)$ & $2.19(1.70-2.68)$ & .21 \\
\hline Question 6: Confidence to leave home because of lung conditions & $0.56(0.33-0.78)$ & $0.67(0.33-1.02)$ & .66 \\
\hline Question 7: Sleep quality & $1.18(0.91-1.45)$ & $1.60(1.10-2.11)$ & .34 \\
\hline Question 8: Amount of energy & $2.21(1.89-2.53)$ & $2.35(1.91-2.79)$ & .53 \\
\hline
\end{tabular}




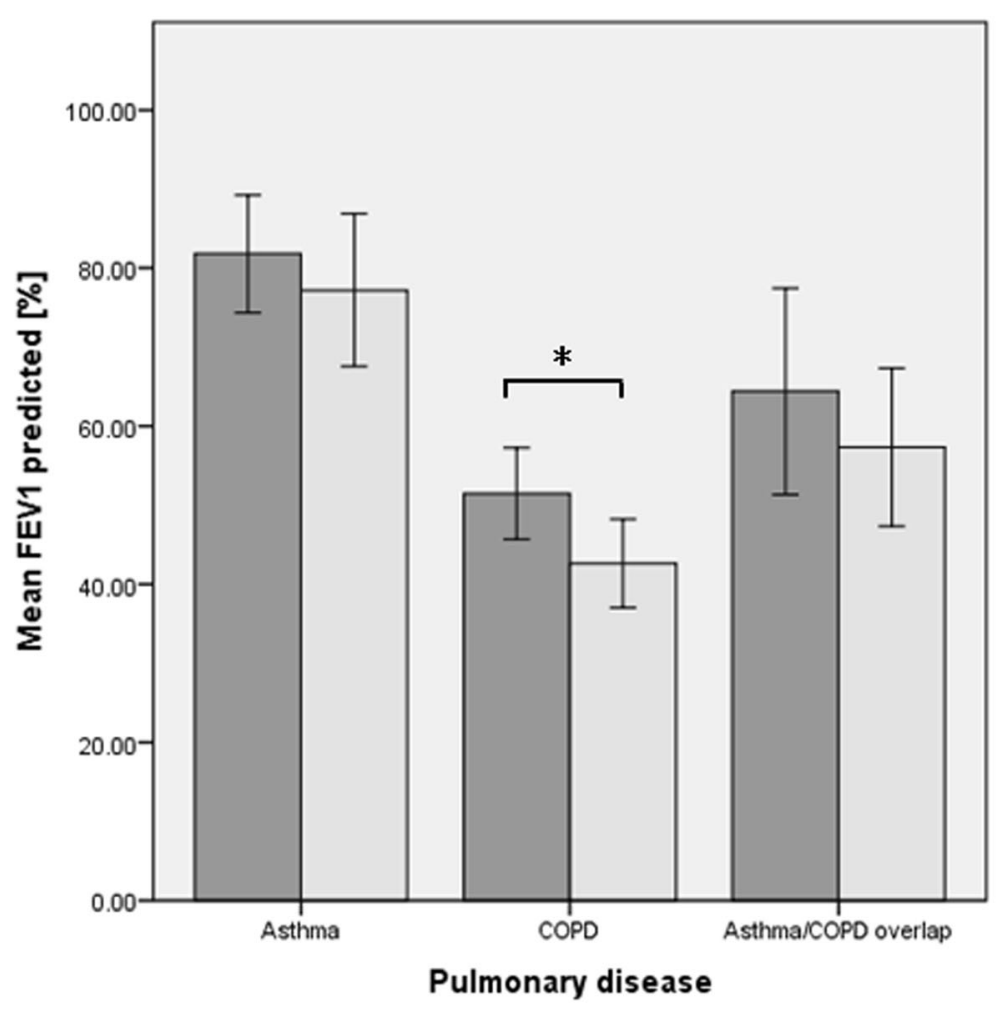

Device

application

口correct

Dincorrect

error bars: $95 \% \mathrm{Cl}$

Fig. 3 Comparison of the mean $\mathrm{FEV}_{1} \%$ predicted in patients applying their devices corrects an incorrect. $\mathrm{FEV}_{1}$, forced expiratory volume in one second

inhaler used and the asthma disease outcome. Participants, who applied easier-to-use-inhalers and therefore had higher numbers of correct device applications showed better disease control [31].

A significant difference in the CAT sum score was found when comparing COPD patients with correct and incorrect device application. Patients with an incorrect device application reported a higher impact of their disease on their health status. Subgroup analyses taking into account individual CAT questions revealed significant differences for symptoms like coughing and breathlessness. This may be explained by the fact that patients who apply the inhaler devices incorrectly are not expected to fully benefit from the effect of the prescribed medication, leading to more COPD symptoms like coughing and breathlessness during efforts. Furthermore, uncontrolled symptoms may adversely affect patients' attitudes towards their medication. If they have the feeling that a therapy is not working, their adherence will be correspondingly low and the patient will no longer inhale the medication $[27,32,33]$.

\section{Lung function parameters and correct/incorrect device application at baseline}

Interestingly, no differences were found for $\mathrm{FEV}_{1}$ in asthma patients at baseline when comparing correct versus incorrect device application. As mentioned before, the average $\mathrm{FEV}_{1}$ was very high at baseline, providing a reasonable explanation for this finding. Nevertheless, this demonstrates once again that asthma patients may have no tangible impairment of their lung function during a stable phase and that even severely impaired lung function may be fully reversible after acute exacerbations.

However, significantly higher $\mathrm{FEV}_{1}$ values were found in COPD patients who applied their devices correctly compared to those patients who did not. This finding underlines the results from previous studies revealing that correct and sustained use of inhaled medication is associated with a reduced loss of lung function and an improvement in quality of life [34-37].

\section{Limitations}

This cross-sectional analysis is based on data assessed at the beginning of the Adherence-Trial. We have no information about the course of the lung disease and medication adjustments before inclusion, since these were not recorded. Therefore, results should be interpreted with caution.

Furthermore, since the patients had to be in a stable and exacerbation-free phase four week before inclusion, there is a bias regarding the health status of the study patients. Most patients described good health and good 


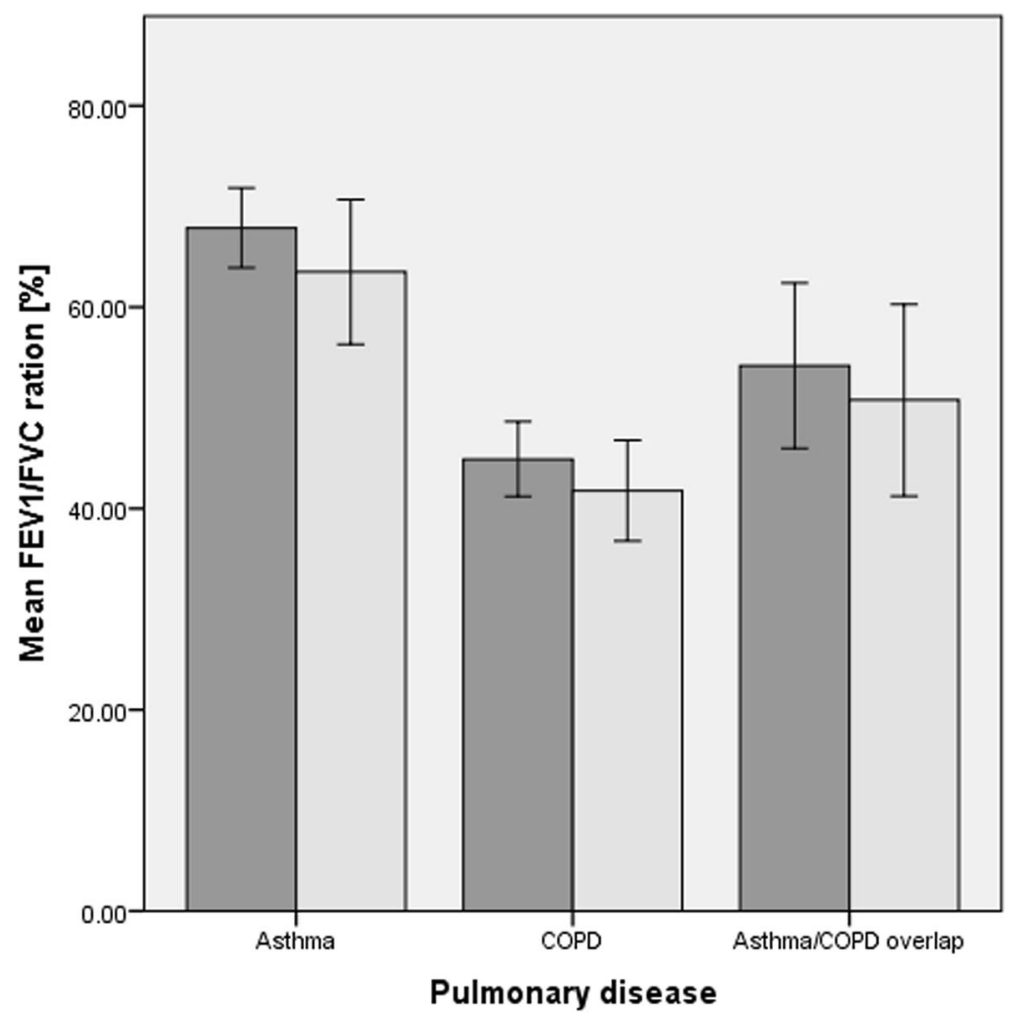

Device

application

$\square$ correct

$\square$ incorrect

error bars: $95 \% \mathrm{Cl}$

Fig. 4 Comparison of the mean $\mathrm{FEV}_{1} / \mathrm{FVC} \%$ predicted in patients applying their devices correct and incorrect. FEV ${ }_{1}$, forced expiratory volume in one second; FVC, forced vital capacity

quality of life at baseline. This could lead to overestimation of the patient's health status and quality of life at the start of the study.

Due to sub analyses using the individual lung diseases (asthma, COPD, asthma-COPD overlap) a limited power must be expected for the investigations which were subdivided in the subclasses, which represents a further limitation.

In addition, the investigator who evaluated the device application of the patients was not blinded to the patient's QoL scores and lung function parameters, which represents a potential source of bias. In order to diminish this bias, the chronological order of the clinical visits was set in a way that the evaluation of the device application was performed as a first step and after that all the other assessments (lung function tests, questionnaires, etc.) were performed. However, always the same person evaluated the device application, in order to avoid the possibility of interrater variability for the evaluation.

Patients were aware that their inhalation technique was evaluated, which consequently introduces further bias. To minimize these bias, patients were blinded to which steps were defined as critical and that they had to reach a maximal total score to be evaluated as correct.

\section{Conclusion}

To knowledge, this study is one of the first to investigate a population affected by both, asthma and COPD and with no imposed restrictions regarding inhaler devices. Therefore, the application of all available inhaler devices could be investigated and analysed. Due to the wide selection of patients, the present data helps to describe the study population with respect to individual inhalation skills and to get an insight into the current primary care situation looks like. This, enables to derive implications for future care regarding inhalation techniques. This study suggests that regular and comprehensive training of correct inhalation technique is mandatory in patients with chronic lung disease in particular in patients with COPD. Patients who apply their prescribed inhaled medication correctly seem to experience less impact of the disease on their health status and less limitation in their lung function. Moreover, the evaluated data showed that participants who handled their devices correctly had a significantly smaller history of exacerbations 


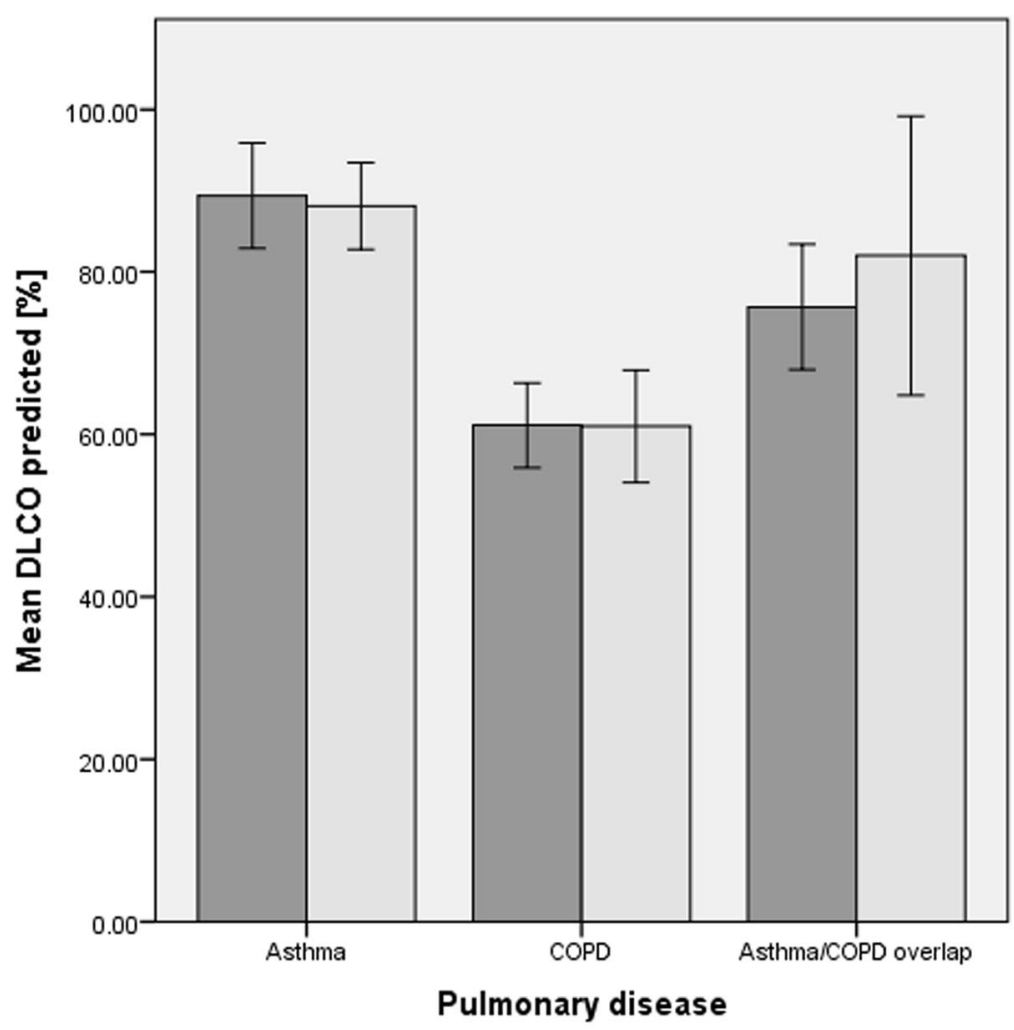

Device application

$\square$ correct

口incorrect

error bars: $95 \% \mathrm{Cl}$

Fig. 5 Comparison of the mean DLCO \% predicted in patients applying their devices correct and incorrect. DLCO, diffusing capacity of the lung for carbon monoxide

compared to participants with device handling errors, which also included critical errors. The findings from this study should encourage health professionals to continuously provide instructions on correct inhalation technique and to re-evaluate the patient's inhalation technique on a regular basis. By increasing the patient's responsibility as well as integrating him or her into the treatment process, faulty use of inhalation devices can be prevented in the long term with beneficial effects on signs, symptoms and progression of disease. In order to make a meaningful statement, these results should be confirmed by further analyses that evaluate the disease control, therapy usage and adjustments during the months before study inclusion in more detail. Since the correct application of an inhaler by patients is directly associated with the efficacy of the therapy, the choice of the inhalation devices represents an important step in order to achieve therapeutic success. Therefore, it is proposed that future studies should investigate the preferences and the handling skills of different patient categories in order to ensure a suitable device choice which is individualized according to the patient's need whenever possible.

\section{Abbreviations}

ACO: Asthma-COPD-Overlap; ACT: Asthma Control Test; BMl: Body mass index; CAT: COPD Assessment Test; COPD: Chronic Obstructive Pulmonary Disease; DLCO: Diffusing capacity of the lung for carbon monoxide; $\mathrm{FEV}_{1}$ : Forced expiratory volume in one second; FVC: Forced vital capacity; GINA: Global Initiative for Asthma; GOLD: Global Initiative for Chronic Obstructive Lung Disease; ICS: Inhaled corticosteroid; LABA: Long acting beta 2 - agonist; LAMA: Long acting muscarinic antagonist; PY: Pack years;

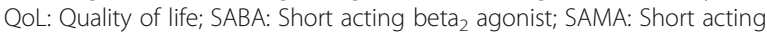
muscarinic antagonist; SD: Standard deviation; SGRQ: St. George Respiratory Questionnaire

\section{Acknowledgments}

Special thanks to the following institution and departments for their support in recruitment of the study patients: Marketing Department (Cantonal Hospital Baselland, Liestal, Switzerland), Dr. med. A. Breitenbücher (pulmonologist, Cantonal Hospital Baselland, Bruderholz, Switzerland), Dr. med. L. Joos Zellweger (pulmonologist, Claraspital, Basel, Switzerland), Dr. med. S. Vogt (pulmonologist, Hospital Rheinfelden, Rheinfelden, Switzerland), Dr. med. M. Frey (pulmonologist, Clinic Barmelweid, Barmelweid, Switzerland) and Dr. med. D. Simonett, pulmonologist in private practice, Liestal,

Switzerland). Thank you also to Anne Leuppi-Teagtmeyer for the English proof reading of this manuscript.

\section{Funding}

This project was financially supported by grants from the Gottfried und Julia Bangerter-Rhyner Foundation, Bern, Switzerland, the Swiss Academy of Medical Sciences (SAMW), Bern, Switzerland, the Freiwillige Akademische Gesellschaft (FAG), Basel, Switzerland and the Swiss Lung League, Berne, Switzerland. Further financial support was provided by unrestricted grands 
from Boehringer Ingelheim Switzerland, Astra Zeneca Switzerland and Mundipharma Switzerland.

The funding agencies respectively pharmaceutical companies have no bearing on the study design, data collection and analysis or writing of the manuscript.

\section{Availability of data and materials}

The used raw data during this study are available from the corresponding author on reasonable request.

\section{Authors' contributions}

$C G, T D$ and $J D L$ are the chief investigators of the project. CG, TD, SD, AB, IA, $\mathrm{KH}$ and JDL made contributions to the protocol within the scope of their specific areas of expertise. CG prepared the first draft of this manuscript and all authors revised the paper critically for important intellectual content and gave approval for the final version. CG recruited the study patients, controlled the adherence of the patients, did the intervention, if necessary, and contributed to the data collection during the follow-up visits. ALB and SM contributed to the recruitment of the study patients with a lot of patience and to the data collection during baseline and follow-up visits.

\section{Ethics approval and consent to participate}

The study was approved by the Ethics Committee northwest/central Switzerland (EK- 269/13). Written informed consent was obtained from all participants prior to study entry.

\section{Consent for publication}

Not applicable.

\section{Competing interests}

The authors declare that they have no competing interests.

\section{Publisher's Note}

Springer Nature remains neutral with regard to jurisdictional claims in published maps and institutional affiliations.

\section{Author details}

${ }^{1}$ University Clinic of Medicine, Cantonal Hospital Baselland, Rheinstrasse 26, $\mathrm{CH}$ - 4410 Liestal, Switzerland. ${ }^{2}$ Department of Pharmaceutical Sciences, University of Basel, Basel, Switzerland. ${ }^{3}$ Faculty of Medicine, University of Basel, Basel, Switzerland.

\section{Received: 16 August 2018 Accepted: 12 November 2018} Published online: 03 December 2018

\section{References}

1. World Health Organization. Global suveillance, prevention and control of chronic respiratory diseases: a comprehensive approach. 2007. Available: http://www.who.int/gard/publications/GARD\%20Book\%202007.pdf. Accessed 30 July 2018.

2. Melani AS, Bonavia M, Cilenti $V$, Cinti C, Lodi M, Martucci $P$, et al. Inhaler mishandling remains common in real life and is associated with reduced disease control. Respir Med. 2011;105(6):930-8.

3. Lindgren S, Bake B, Larsson S. Clinical consequences of inadequate inhalation technique in asthma therapy. Eur J Respir Dis. 1987;70(2):93-8.

4. Virchow JC, Crompton GK, Dal Negro R, Pedersen S, Magnan A, Seidenberg $J$, et al. Importance of inhaler devices in the management of airway disease. Respir Med. 2008;102(1):10-9.

5. Global strategy of Asthma Management and Prevention. 2017. Global Initiative for Asthma. Available: https://ginasthma.org/wp-content/uploads/ 2017/02/wmsGINA-2017-main-report-final_V2.pdf. Accessed 30 July 2018

6. Fink JB, Rubin BK. Problems with inhaler use: a call for improved clinician and patient education. Respir Care. 2005;50(10):1360-74; discussion 74-5.

7. Carrion Valero F, Maya Martinez M, Fontana Sanchis I, Diaz Lopez J, Marin Pardo J. Inhalation technique in patients with chronic respiratory diseases. Arch Bronconeumol. 2000;36(5):236-40.

8. Girodet PO, Raherison C, Abouelfath A, Lignot S, Deport F, Moore N, et al. Real-life use of inhaler devices for chronic obstructive pulmonary disease in primary care. Therapie. 2003;58(6):499-504.
9. Molimard M, Raherison C, Lignot S, Depont F, Abouelfath A, Moore N. Assessment of handling of inhaler devices in real life: an observational study in 3811 patients in primary care. J Aerosol Med. 2003;16(3):249-54.

10. Shrestha M, Parupia H, Andrews B, Kim SW, Martin MS, Park DI, et al. Metereddose inhaler technique of patients in an urban ED: prevalence of incorrect technique and attempt at education. Am J Emerg Med. 1996;14(4):380-4.

11. Erickson SR, Horton A, Kirking DM. Assessing metered-dose inhaler technique: comparison of observation vs. patient self-report. J Asthma. 1998; 35(7):575-83.

12. Gregoriano C, Dieterle T, Durr S, Arnet I, Hersberger KE, Leuppi JD. Impact of an Electronic Monitoring Intervention to Improve Adherence to Inhaled Medication in Patients with Asthma and Chronic Obstructive Pulmonary Disease: Study Protocol for a Randomized Controlled Trial. JMIR Res Protoc. 2017;6(10):e204.

13. Deutsche Atemwegsliga e.V. Richtig inhalieren. Available: http://www. atemwegsliga.de/richtig-inhalieren.html. Accessed 30 July 2018.

14. Miller MR, Hankinson J, Brusasco V, Burgos F, Casaburi R, Coates A, et al. Standardisation of spirometry. Eur Respir J. 2005;26(2):319-38.

15. van der Palen J, Thomas M, Chrystyn H, Sharma RK, van der Valk PD, Goosens M, et al. A randomised open-label cross-over study of inhaler errors, preference and time to achieve correct inhaler use in patients with COPD or asthma: comparison of ELLIPTA with other inhaler devices. NPJ Prim Care Respir Med. 2016;26:16079.

16. Nathan RA, Sorkness CA, Kosinski M, Schatz M, Li JT, Marcus P, et al. Development of the asthma control test: a survey for assessing asthma control. J Allergy Clin Immunol. 2004;113(1):59-65.

17. Jones PW, Harding G, Berry P, Wiklund I, Chen WH, Kline Leidy N. Development and first validation of the COPD Assessment Test. Eur Respir J. 2009;34(3):648-54.

18. Jones PW, Quirk FH, Baveystock CM. The St George's Respiratory Questionnaire. Respir Med. 1991;85(Suppl B):25-31; discussion 3-7.

19. Jones PW, Quirk FH, Baveystock CM, Littlejohns P. A self-complete measure of health status for chronic airflow limitation. The St. George's Respiratory Questionnaire. Am Rev Respir Dis. 1992;145(6):1321-7.

20. Guenette L, Breton MC, Gregoire JP, Hobin MS, Bolduc Y, Boulet LP, et al. Effectiveness of an asthma integrated care program on asthma control and adherence to inhaled corticosteroids. J Asthma. 2015;52(6):638-45.

21. Durr S, Hersberger KE, Zeller A, Scheuzger J, Miedinger D, C.Gregoriano, et al. The Integrated Care of Asthma in Switzerland (INCAS) Study: Changes in Asthma Control and Perception of Health Care through Asthma Education. Respiration. 2017;94(5):416-423.

22. Tommelein E, Mehuys E, Van Hees T, Adriaens E, Van Bortel L, Christiaens T, et al. Effectiveness of pharmaceutical care for patients with chronic obstructive pulmonary disease (PHARMACOP): a randomized controlled trial. Br J Clin Pharmacol. 2014;77(5):756-66.

23. Price DB, Roman-Rodriguez M, McQueen RB, Bosnic-Anticevich S, Carter V, Gruffydd-Jones K, et al. Inhaler Errors in the CRITIKAL Study: Type, Frequency, and Association with Asthma Outcomes. J Allergy Clin Immunol Pract. 2017:5(4):1071-81 e9.

24. Kiser K, Jonas D, Warner Z, Scanlon K, Shilliday BB, DeWalt DA. A randomized controlled trial of a literacy-sensitive self-management intervention for chronic obstructive pulmonary disease patients. J Gen Intern Med. 2012;27(2):190-5.

25. Hesselink AE, Penninx BW, Wijnhoven HA, Kriegsman DM, van Eijk JT. Determinants of an incorrect inhalation technique in patients with asthma or COPD. Scand J Prim Health Care. 2001;19(4):255-60.

26. Diamond SA, Chapman KR. The impact of a nationally coordinated pharmacybased asthma education intervention. Can Respir J. 2001;8(4):261-5.

27. Hodder R, Price D. Patient preferences for inhaler devices in chronic obstructive pulmonary disease: experience with Respimat Soft Mist inhaler. Int J Chron Obstruct Pulmon Dis. 2009:4:381-90.

28. Global Strategy for the Diagnosis, management and prevention of chronic obstructive pulmonary Diseases. 2017. Global Initiative for Chronic Obstructive Lung Disease. Available: http://goldcopd.org/gold-2017-globalstrategy-diagnosis-management-prevention-copd/. Accessed 30 July 2018.

29. Price D, Haughney J, Sims E, Ali M, von Ziegenweidt J, Hillyer EV, et al. Effectiveness of inhaler types for real-world asthma management: retrospective observational study using the GPRD. J Asthma Allergy. 2011;4:37-47.

30. Molimard M, Raherison C, Lignot S, Balestra A, Lamarque S, Chartier A, et al. Chronic obstructive pulmonary disease exacerbation and inhaler device 
handling: real-life assessment of 2935 patients. Eur Respir J. 2017;49: 1601794.

31. Price D, Thomas M, Mitchell G, Niziol C, Featherstone R. Improvement of asthma control with a breath-actuated pressurised metred dose inhaler (BAl): a prescribing claims study of 5556 patients using a traditional pressurised metred dose inhaler (MDI) or a breath-actuated device. Respir Med. 2003;97(1):1-9.

32. Rand CS. Patient adherence with COPD therapy. Eur Resir Rev. 2005;14(96): 97-101.

33. Jones RC, Hyland ME, Hanney K, Erwin J. A qualitative study of compliance with medication and lifestyle modification in Chronic Obstructive Pulmonary Disease (COPD). Prim Care Respir J. 2004;13(3):149-54.

34. Celli BR, Thomas NE, Anderson JA, Ferguson GT, Jenkins CR, Jones PW, et al. Effect of pharmacotherapy on rate of decline of lung function in chronic obstructive pulmonary disease: results from the TORCH study. Am J Respir Crit Care Med. 2008;178(4):332-8.

35. Suissa S, Ernst P, Vandemheen KL, Aaron SD. Methodological issues in therapeutic trials of COPD. Eur Respir J. 2008;31(5):927-33

36. Decramer M, Celli B, Kesten S Lystig T, Mehra S, Tashkin DP, et al. Effect of tiotropium on outcomes in patients with moderate chronic obstructive pulmonary disease (UPLIFT): a prespecified subgroup analysis of a randomised controlled trial. Lancet. 2009:374(9696):1171-8.

37. Tashkin DP, Celli B, Senn S, Burkhard D, Kesten S, Menjoge S, et al. A 4-year trial of tiotropium in chronic obstructive pulmonary disease. N Engl J Med. 2008;359(15):1543-54.

38. Food and Drug Administration. Drug Safety Communication 2017. Available: http://www.fda.gov/Drugs/DrugSafety/ucm589587.htm. Accessed 23 Oct 2018.

Ready to submit your research? Choose BMC and benefit from:

- fast, convenient online submission

- thorough peer review by experienced researchers in your field

- rapid publication on acceptance

- support for research data, including large and complex data types

- gold Open Access which fosters wider collaboration and increased citations

- maximum visibility for your research: over $100 \mathrm{M}$ website views per year

At $\mathrm{BMC}$, research is always in progress.

Learn more biomedcentral.com/submissions 